\title{
Effect of matrix material on the morphology and optical properties of InP-based InAsSb nanostructures
}

\author{
W. Lei, ${ }^{\text {a) }}$ H. H. Tan, and C. Jagadish \\ Department of Electronic Materials Engineering, Research School of Physics and Engineering, \\ The Australian National University, Canberra, Australian Capital Territory 0200, Australia
}

(Received 13 August 2009; accepted 16 September 2009; published online 9 October 2009)

\begin{abstract}
This paper presents a study on the effect of matrix material on the morphology and optical properties of self-assembled InP-based InAsSb nanostructures. Due to the differences in surface roughness of the growth front, $\mathrm{In}_{0.53} \mathrm{Ga}_{0.47} \mathrm{As}$ matrix layer induces the formation of short quantum dashes (QDashes) and elongated quantum dots, while $\mathrm{InP}$ and $\mathrm{In}_{0.52} \mathrm{Al}_{0.48} \mathrm{As}$ matrix layers promote the formation of long QDashes and quantum wires, respectively. The shape anisotropy of InAsSb nanostructures on $\mathrm{In}_{0.53} \mathrm{Ga}_{0.47} \mathrm{As}$, $\mathrm{InP}$, and $\mathrm{In}_{0.52} \mathrm{Al}_{0.48} \mathrm{As}$ layers is further investigated with polarized photoluminescence measurements. The InAsSb nanostructures show a luminescence polarization degree of $8.5 \%, 14.3 \%$, and $29 \%$ for $\mathrm{In}_{0.53} \mathrm{Ga}_{0.47} \mathrm{As}$, InP, and $\mathrm{In}_{0.52} \mathrm{Al}_{0.48} \mathrm{As}$ matrixes, which corresponds well with the shape anisotropy observed with atomic force microscope. Furthermore, InAsSb $/ \mathrm{In}_{0.53} \mathrm{Ga}_{0.47} \mathrm{As}$ nanostructures also show the longest, thermally stable emission wavelength, which serves as a promising material system for fabricating midinfrared emitters. (c) 2009 American Institute of Physics. [doi:10.1063/1.3246165]
\end{abstract}

Recently, much effort has been devoted to InP-based InAsSb nanostructures ${ }^{1-5}$ due to their promising applications in midinfrared 2-3 $\mu \mathrm{m}$ emitters, ${ }^{6-8}$ which have a wide range of applications in military, telecommunication, molecular spectroscopy, biomedical surgery, environmental protection and manufacturing industry applications. As reported in previous work, the incorporation of antimony $(\mathrm{Sb})$ into InAs quantum dots (QDs) causes dramatic change to island morphology, leading to the formation of high density of flat InAsSb quantum dashes (QDashes). ${ }^{5,9,10}$ This is mainly induced by the surfactant effect of $\mathrm{Sb}$ atoms and the large lattice mismatch between InAsSb and InP. As indicated by previous work on InP-based InAs QDs, the type of buffer layer has a significant influence on the morphology and physical properties of the self-assembled nanostructures. ${ }^{11,12}$ In this work, the effect of buffer material $\left(\mathrm{In}_{0.53} \mathrm{Ga}_{0.47} \mathrm{As}\right.$, InP, and $\mathrm{In}_{0.52} \mathrm{Al}_{0.48} \mathrm{As}$ ) on the morphology and optical properties of InAsSb nanostructures is investigated. $\mathrm{In}_{0.53} \mathrm{Ga}_{0.47} \mathrm{As}$ layer prefers to induce the formation of InAsSb elongated QDs and short dashes, while InP and $\mathrm{In}_{0.52} \mathrm{Al}_{0.48} \mathrm{As}$ promote the formation of long InAsSb dashes and quantum wires (QWRs), respectively. InAsSb/ $\mathrm{In}_{0.53} \mathrm{Ga}_{0.47} \mathrm{As}$ nanostructures are also shown to be favorable for achieving long emission wavelength with good thermal stability.

The samples were grown on semi-insulating InP (001) substrates in a horizontal flow metal-organic chemical vapor deposition reactor (Aixtron, AIX 200/4) at a pressure of 180 mbar. Trimethylindium (TMIn), trimethylgallium, trimethylaluminum, trimethylantimony (TMSb), $\mathrm{PH}_{3}$, and $\mathrm{AsH}_{3}$ were used as precursors and ultrahigh purity $\mathrm{H}_{2}$ as the carrier gas. The $\mathrm{InAsSb} / \mathrm{In}_{0.53} \mathrm{Ga}_{0.47} \mathrm{As}$ nanostructure sample was grown with the following layer sequence: first, a $100 \mathrm{~nm} \mathrm{InP}$ layer was deposited at $650{ }^{\circ} \mathrm{C}$ followed by a $100 \mathrm{~nm}$ $\mathrm{In}_{0.53} \mathrm{Ga}_{0.47} \mathrm{As}$ also at $650{ }^{\circ} \mathrm{C}$ as the buffer layer. Growth was then interrupted and the growth temperature was dropped to

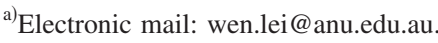

$520{ }^{\circ} \mathrm{C}$ to grow $4 \mathrm{ML}$ InAsSb. The InAsSb were immediately capped with $5 \mathrm{~nm} \mathrm{In}_{0.53} \mathrm{Ga}_{0.47} \mathrm{As}$ at $520{ }^{\circ} \mathrm{C}$. Growth was then interrupted and temperature ramped up to $650{ }^{\circ} \mathrm{C}$ for the deposition of $100 \mathrm{~nm} \operatorname{In}_{0.53} \mathrm{Ga}_{0.47}$ As layer. The same steps were followed to grow a top/surface layer of InAsSb nanostructures for atomic force microscopy (AFM) measurements. The same procedure was used to grow InAsSb/InP and InAsSb $/ \mathrm{In}_{0.52} \mathrm{Al}_{0.48} \mathrm{As}$ nanostructures except the difference in the use of GaAs interlayer and the growth temperature of $\mathrm{In}_{0.52} \mathrm{Al}_{0.48} \mathrm{As}$ layers. For InAsSb/InP nanostructure sample, after the deposition of $100 \mathrm{~nm} \mathrm{InP}$ buffer layer a $0.6 \mathrm{~nm} \mathrm{GaAs}$ interlayer was grown at $650^{\circ} \mathrm{C}$ to minimize As-P exchange and smoothen growth front. ${ }^{13,14}$ As for $\operatorname{InAsSb} / \operatorname{In}_{0.52} \mathrm{Al}_{0.48} \mathrm{As}$ nanostructure sample, the $\mathrm{In}_{0.52} \mathrm{Al}_{0.48} \mathrm{As}$ buffer and cap layers were deposited at $680{ }^{\circ} \mathrm{C}$. A $0.6 \mathrm{~nm} \mathrm{GaAs}$ interlayer was also deposited at $680^{\circ} \mathrm{C}$ to smoothen growth front after the deposition of $\mathrm{In}_{0.52} \mathrm{Al}_{0.48} \mathrm{As}$ layers. During the growth of InAsSb both the TMSb and $\mathrm{AsH}_{3}$ sources were introduced simultaneously with the TMIn precursor. The morphology of top InAsSb nanostructures was characterized by using AFM in tapping mode. The photoluminescence (PL) characteristics of the samples were carried out under excitation by the $637 \mathrm{~nm}$ line of a coherent radius laser. The luminescence signal was collected by a liquid nitrogen-cooled extended InGaAs photodetector through a $0.5 \mathrm{~m}$ monochromator.

Figures 1(a)-1(c) show the typical AFM images of InAsSb nanostructures on $\operatorname{In}_{0.53} \mathrm{Ga}_{0.47} \mathrm{As}$, InP, and $\mathrm{In}_{0.52} \mathrm{Al}_{0.48} \mathrm{As}$ buffer layers, respectively. It is observed that the morphology of InAsSb nanostructures is quite different depending on the buffer material. InAsSb elongated QDs or short QDashes are formed on $\mathrm{In}_{0.53} \mathrm{Ga}_{0.47} \mathrm{As}$ layer, while InAsSb long QDashes and QWRs are obtained on InP and $\mathrm{In}_{0.52} \mathrm{Al}_{0.48} \mathrm{As}$ layers, respectively. The elongated QDs, QDashes, and QWRs are all aligned along the [1-10] direction, which is the typical behavior of self-assembled InAsSb nanostructures. This can be ascribed to the larger migration length of In adatoms along the [1-10] direction induced by 


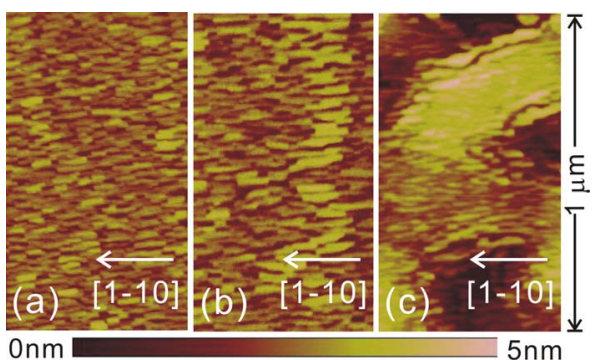

FIG. 1. (Color online) Typical AFM images of InAsSb nanostructures on $\mathrm{In}_{0.53} \mathrm{Ga}_{0.47} \mathrm{As}(\mathrm{a}), \operatorname{InP}(\mathrm{b})$, and $\operatorname{In}_{0.52} \mathrm{Al}_{0.48} \mathrm{As}$ (c) matrixes.

surface anisotropy. The InAsSb/ $\mathrm{In}_{0.53} \mathrm{Ga}_{0.47} \mathrm{As}$ QDashes have an average height of $1.4 \mathrm{~nm}$, width (along the [110] direction) of $23 \mathrm{~nm}$, and length (along the [1-10] direction) of $70 \mathrm{~nm}$, while the InAsSb/InP QDashes show an average height of $1.7 \mathrm{~nm}$, width of $25 \mathrm{~nm}$, and length of $105 \mathrm{~nm}$. As for InAsSb/ $\operatorname{In}_{0.52} \mathrm{Al}_{0.48} \mathrm{As}$ QWRs, their average height and width are around 1.8 and $24 \mathrm{~nm}$, while their average length is about $200 \mathrm{~nm}$. Despite the large difference in their lengths, the InAsSb islands formed on different buffer layers exhibit similar height and width. This is mainly caused by the surfactant effect of $\mathrm{Sb}$ atoms, the details of which have been described in Ref. 5. The difference in InAsSb lengths can mainly be attributed to the difference in surface roughness or surface anisotropy of growth front on $\mathrm{In}_{0.53} \mathrm{Ga}_{0.47} \mathrm{As}$, InP and $\mathrm{In}_{0.52} \mathrm{Al}_{0.48} \mathrm{As}$ layers. As shown by previous studies on InAs/ InAlAs nanostructures, ${ }^{15,16}$ the phase separation effect in InAlAs alloy is quite significant, and could lead to wirelike In-rich and Al-rich regions (aligned along the [1-10] direction) on InAlAs surface. The wirelike In-rich regions may provide preferential nucleation sites for the newly deposited In adatoms due to the small misfit strain energy though a $0.6 \mathrm{~nm}$ GaAs smoothening layer is used, leading to the formation of InAsSb QWRs. As for InGaAs matrix, the phase separation effect in InGaAs alloy is quite weak and no Inrich regions are formed, resulting in the formation of short InAsSb QDashes or elongated QDs. ${ }^{17}$ The formation of long InAsSb/InP QDashes could also be associated with the significant surface anisotropy of InP buffer layer induced by $(2 \times 4)$ reconstruction, as suggested by previous work on InAs/InP nanostructures. ${ }^{18,19}$ Though a $0.6 \mathrm{~nm}$ GaAs interlayer is used to minimize the As-P exchange and smoothen the growth front, the surface anisotropy of growth front may still be obvious and leads to the formation of long InAsSb QDashes. ${ }^{13,14}$

The shape anisotropy of InAsSb islands grown on $\mathrm{In}_{0.53} \mathrm{Ga}_{0.47} \mathrm{As}$, InP, and $\mathrm{In}_{0.52} \mathrm{Al}_{0.48} \mathrm{As}$ matrixes is also studied by polarized PL (PPL) measurements. Figures 2(a)-2(c) show the polarized PL spectra and linear polarization degrees of the three samples at $77 \mathrm{~K}$. Obviously, $\mathrm{InAsSb} / \mathrm{In}_{0.53} \mathrm{Ga}_{0.47} \mathrm{As}$ nanostructures have the longest emission wavelength $(\sim 1.77 \mu \mathrm{m}$ at $77 \mathrm{~K})$ compared with InAsSb/InP and InAsSb $/ \operatorname{In}_{0.52} \mathrm{Al}_{0.48} \mathrm{As}$ nanostructures, which is mainly caused by the lower confinement barrier of the $\mathrm{In}_{0.53} \mathrm{Ga}_{0.47}$ As layers. As shown in Fig. 2, the linear PL polarization anisotropy of InAsSb nanostructures is different depending on the buffer material. The degree of linear polarization $(P)$ is defined by $p=\left(I_{\|}-I_{\perp}\right) /\left(I_{\|}+I_{\perp}\right)$, where $I_{\|}\left(I_{\perp}\right)$ is the intensity of the luminescence polarizing along the [1-10] ([110]) direction. ${ }^{20}$ The $P$ values of the InAsSb islands are around $8.5 \%, 14.3 \%$, and $29 \%$ for $\operatorname{In}_{0.53} \mathrm{Ga}_{0.47} \mathrm{As}$, InP, and


FIG. 2. (Color online) $77 \mathrm{~K}$ polarized PL spectra and linear PL polarization degrees of $\operatorname{InAsSb} / \mathrm{In}_{0.53} \mathrm{Ga}_{0.47} \mathrm{As}$ (a), InAsSb/InP (b), and InAsSb/ $\mathrm{In}_{0.52} \mathrm{Al}_{0.48} \mathrm{As}$ (c) nanostructures.

$\mathrm{In}_{0.52} \mathrm{Al}_{0.48} \mathrm{As}$ buffer layers, respectively, at their PL peak positions. These values are independent of the incident light polarization. Principally, the linear PL polarization anisotropy is mainly determined by the shape anisotropy of InAsSb nanostructures though strain may also play a role. The larger the shape anisotropy of InAsSb nanostructures, the larger the degree of linear polarization. The $P$ values obtained for InAsSb nanostructures on $\mathrm{In}_{0.53} \mathrm{Ga}_{0.47} \mathrm{As}$, InP, and $\mathrm{In}_{0.52} \mathrm{Al}_{0.48} \mathrm{As}$ buffer layers are consistent well with the shape anisotropy of InAsSb nanostructures observed with AFM measurements.

To further investigate the effect of buffer material on their optical properties, temperature dependent PL measurements are performed on the InAsSb nanostructures. Figure 3(a) shows the temperature dependence of PL energy of the InAsSb nanostructures on $\operatorname{In}_{0.53} \mathrm{Ga}_{0.47} \mathrm{As}$, InP and $\mathrm{In}_{0.52} \mathrm{Al}_{0.48} \mathrm{As}$ buffer layers. For comparison, the Varshini law of bulk InAsSb band-gap energy with temperature is also plotted in Fig. 3(a). ${ }^{21}$ It is observed that the rates of red-shift of the PL peaks of InAsSb/InP and InAsSb/ $\operatorname{In}_{0.52} \mathrm{Al}_{0.48} \mathrm{As}$ nanostructures are slightly faster than that of Varshini law, which is the typical temperature behavior of QDs and QWRs, and can be mainly attributed to carrier redistribution among nanostructures with different sizes. In the temperature range of $13-300 \mathrm{~K}$, the energy shifts are around 44 and $51 \mathrm{meV}$ for InAsSb/InP and $\mathrm{InAsSb} / \mathrm{In}_{0.52} \mathrm{Al}_{0.48} \mathrm{As}$ nanostructures, respectively, which are much less than the re- 




FIG. 3. (Color online) Temperature dependence of PL peak energy (a) and integrated PL intensity (b) of InAsSb nanostructures embedded in $\mathrm{In}_{0.53} \mathrm{Ga}_{0.47} \mathrm{As}$, InP, and $\mathrm{In}_{0.52} \mathrm{Al}_{0.48} \mathrm{As}$ matrixes. Please note that the integrated PL intensity of $\mathrm{InAsSb} / \mathrm{In}_{0.53} \mathrm{Ga}_{0.47} \mathrm{As}$ nanostructures has been multiplied by seven for easy comparison.

ported value of $60 \sim 80 \mathrm{meV}$ for InAs/InP QDs. ${ }^{20}$ This indicates a more homogeneous size distribution of InAsSb nanostructures compared with the InAs/InP QDs. As for $\mathrm{InAsSb} / \mathrm{In}_{0.53} \mathrm{Ga}_{0.47} \mathrm{As}$ nanostructures it is noted that below $90 \mathrm{~K}$, the PL energy is essentially unchanged. When the temperature is increased further, the PL peak starts to shift to lower energy side, but the redshift rate is slower than that of Varshni law. Though the reason for this unusual temperature behavior of PL peak energy of InAsSb/ $\mathrm{In}_{0.53} \mathrm{Ga}_{0.47} \mathrm{As}$ nanostructures is not well understood yet, it does demonstrate their great potential for making emitters with good thermal stability.

The integrated PL intensity $\left(I_{\mathrm{PL}}\right)$ of the InAsSb nanostructures versus temperature is shown in Fig. 3(b). The $I_{\mathrm{PL}}$ starts to drop quickly when the temperature increases over 80, 30, and $50 \mathrm{~K}$ for $\mathrm{InAsSb} / \mathrm{In}_{0.53} \mathrm{Ga}_{0.47} \mathrm{As}$, InAsSb/InP, and $\mathrm{InAsSb} / \mathrm{In}_{0.52} \mathrm{Al}_{0.48} \mathrm{As}$ nanostructures, respectively. It drops to $0.2 \%(6.7 \%, 27 \%)$ of its value at $13 \mathrm{~K}$ when the temperature increases to $210 \mathrm{~K}(300 \mathrm{~K}, 300 \mathrm{~K})$ for InAsSb nanostructures on $\operatorname{In}_{0.53} \mathrm{Ga}_{0.47} \mathrm{As}\left(\mathrm{InP}, \mathrm{In}_{0.52} \mathrm{Al}_{0.48} \mathrm{As}\right)$ buffer layer. The strong quenching of PL intensity of $\mathrm{InAsSb} / \mathrm{In}_{0.53} \mathrm{Ga}_{0.47} \mathrm{As}$ nanostructures can be mainly attributed to the high thermal escape rate of the carriers caused by the lower confinement barrier of $\operatorname{In}_{0.53} \mathrm{Ga}_{0.47}$ As layers. By using an Arrhenius plot with dual activation energies to fit the $I_{\mathrm{PL}}$ at high temperatures, ${ }^{22}$ the thermal activation energy $\left(E_{b}\right)$ values are determined to be 95, 66 and $43 \mathrm{meV}$ for the InAsSb/ $\mathrm{In}_{0.53} \mathrm{Ga}_{0.47} \mathrm{As}$, InAsSb/InP and $\mathrm{InAsSb} / \mathrm{In}_{0.52} \mathrm{Al}_{0.48} \mathrm{As}$ nanostructures, respectively. Considering the PL energy of InAsSb nanostructures, the band gap of $\operatorname{In}_{0.53} \mathrm{Ga}_{0.47} \mathrm{As}$ matrix, and the band offset between the conduction and valence bands, ${ }^{23,24}$ the $I_{\mathrm{PL}}$ quenching of $\mathrm{InAsSb} / \mathrm{In}_{0.53} \mathrm{Ga}_{0.47} \mathrm{As}$ nanostructures at high temperatures can be considered to be dominated by thermal escape of the carriers. Principally, InAsSb/InP and InAsSb/ $\operatorname{In}_{0.52} \mathrm{Al}_{0.48} \mathrm{As}$ nanostructures have larger thermal activation energies due to their higher confinement barriers compared with InAsSb $/ \mathrm{In}_{0.53} \mathrm{Ga}_{0.47} \mathrm{As}$ nanostructures. The smaller $E_{b}$ values indicate that the PL intensity quenching of InAsSb/InP and $\operatorname{InAsSb} / \operatorname{In}_{0.52} \mathrm{Al}_{0.48} \mathrm{As}$ nanostructures at high temperature is associated with not only the thermal escape of the carriers to barriers but also other reasons such as defects. The existence of defects in the InAsSb/InP and InAsSb/InAlAs samples is quite possible due to the rough growth front on InP and $\mathrm{In}_{0.52} \mathrm{Al}_{0.48} \mathrm{As}$ layer. As shown in Fig. 1(c), the surface of $\mathrm{InAsSb} / \mathrm{In}_{0.52} \mathrm{Al}_{0.48} \mathrm{As}$ sample is very rough, which might lead to the formation of defects.

In conclusion, the effect of matrix materials $\left(\mathrm{In}_{0.53} \mathrm{Ga}_{0.47} \mathrm{As}\right.$, InP, and $\left.\operatorname{In}_{0.52} \mathrm{Al}_{0.48} \mathrm{As}\right)$ on the morphology and optical properties of InAsSb nanostructures has been investigated. The $\mathrm{In}_{0.53} \mathrm{Ga}_{0.47} \mathrm{As}$ matrix prefers to induce the formation of elongated InAsSb QDs and short QDashes with long emission wavelength, while $\mathrm{InP}$ and $\operatorname{In}_{0.52} \mathrm{Al}_{0.48} \mathrm{As}$ matrixes prefer to induce the formation of InAsSb long QDashes and QWRs with shorter emission wavelength. The emission wavelength of $\mathrm{InAsSb} / \mathrm{In}_{0.53} \mathrm{Ga}_{0.47} \mathrm{As}$ nanostructures also shows good thermal stability. Therefore, InAsSb $/ \mathrm{In}_{0.53} \mathrm{Ga}_{0.47} \mathrm{As}$ system provides a promising path to achieve InAsSb QD emitters in the 2-3 $\mu \mathrm{m}$ region if some high energy confinement barriers are used to further enhance their temperature characteristics.

Financial support from Australian Research Council is gratefully acknowledged. Facilities used in this work are supported by the Australian National Fabrication Facility.

${ }^{1}$ C. Cornet, F. Doré, A. Ballestar, J. Even, N. Bertru, A. Le Corre, and S. Loualiche, J. Appl. Phys. 98, 126105 (2005).

${ }^{2}$ Y. Qiu and D. Uhl, Appl. Phys. Lett. 84, 1510 (2004).

${ }^{3}$ F. Doré, C. Cornet, P. Caroff, A. Ballestar, J. Even, N. Bertru, O. Dehaese, I. Alghoraibi, H. Folliot, R. Piron, A. Le Corre, and S. Loualiche, Phys. Status Solidi C 3, 3920 (2006).

${ }^{4}$ F. Doré, C. Cornet, A. Schliwa, A. Ballestar, J. Even, N. Bertru, O. Dehaese, I. Alghoraibi, H. Folliot, R. Piron, A. Le Corre, and S. Loualiche, Phys. Status Solidi C 3, 524 (2006).

${ }^{5}$ W. Lei, H. H. Tan, and C. Jagadish, Appl. Phys. Lett. 95, 013108 (2009).

${ }^{6}$ S. Suchalkin, S. Jung, G. Kipshidze, L. Shterengas, T. Hosoda, D. Westerfeld, D. Snyder, and G. Belenky, Appl. Phys. Lett. 93, 081107 (2008).

${ }^{7}$ J. Devenson, R. Teissier, O. Cathabard, and A. N. Baranov, Appl. Phys. Lett. 90, 111118 (2007).

${ }^{8}$ W. Lei and C. Jagadish, J. Appl. Phys. 104, 091101 (2008), and references therein.

${ }^{9}$ K. Kawaguchi, M. Ekawa, T. Akiyama, H. Kuwatsuka, and M. Sugawara, J. Cryst. Growth 291, 154 (2006).

${ }^{10}$ K. Kawaguchi, M. Ekawa, T. Akiyama, H. Kuwatsuka, and M. Sugawara, J. Cryst. Growth 298, 558 (2007).

${ }^{11}$ H. X. Li, T. Daniels-Race, and M.-A. Hasan, Appl. Phys. Lett. 80, 1367 (2002).

${ }^{12}$ Q. D. Zhuang, S. F. Yoon, and H. Q. Zheng, Proceedings of Conference on Optoelectronic and Microelectronic Materials and Devices 2000, Melbourne, Australia, 6-8 December 2000 (unpublished), p. 455.

${ }^{13}$ J. M. Ulloa, S. Anantathanasarn, P. J. van Veldhoven, P. M. Koenraad, and R. Nötzel, Appl. Phys. Lett. 92, 083103 (2008).

${ }^{14}$ S. Anantathanasarn, R. Nötzel, P. J. van Veldhoven, T. J. Eijkemans, and J. H. Wolter, J. Appl. Phys. 98, 013503 (2005).

${ }^{15}$ F. A. Zhao, Y. H. Chen, X. L. Ye, P. Jin, B. Xu, Z. G. Wang, and C. L. Zhang, J. Phys.: Condens. Matter 16, 7603 (2004).

${ }^{16}$ W. Lei, Y. L. Wang, Y. H. Chen, P. Jin, X. L. Ye, B. Xu, and Z. G. Wang, Appl. Phys. Lett. 90, 103118 (2007).

${ }^{17}$ C. Priester and G. Grenet, Phys. Rev. B 61, 16029 (2000).

${ }^{18}$ T. J. Krzyzewski and T. S. Jones, Phys. Rev. B 78, 155307 (2008).

${ }^{19}$ O. Bierwagen and W. T. Masselink, Appl. Phys. Lett. 86, 113110 (2005).

${ }^{20}$ B. Salem, J. Olivares, G. Guillot, G. Bremond, J. Brault, C. Monat, M. Gendry, G. Hollinger, F. Hassen, and H. Maaref, Appl. Phys. Lett. 79, 4435 (2001)

${ }^{21}$ V. K. Dixit, B. Bansal, V. Venkataraman, H. L. Bhat, K. S. Chandrasekharan, and B. M. Arora, J. Appl. Phys. 96, 4989 (2004).

${ }^{22}$ M. Hugues, B. Damilano, J.-Y. Duboz, and J. Massies, Phys. Rev. B 75, 115337 (2007).

${ }^{23}$ I. Vurgaftman, J. R. Meyer, and L. R. Ram-Mohan, J. Appl. Phys. 89, 5815 (2001)

${ }^{24}$ C. Affentauschegg and H. H. Wieder, Semicond. Sci. Technol. 16, 708 (2001) 